\title{
LBL coating of type I collagen and hyaluronic acid on aminolyzed PLLA to enhance the cell-material interaction
}

\author{
M. Y. Zhao ${ }^{1,2}$, L. H. $L i^{1,2^{*}}$, B. $L i^{1}$, C. R. Zhou ${ }^{1,2}$ \\ ${ }^{1}$ Department of Materials Science and Engineering, Jinan University, 510630 Guangzhou, China \\ ${ }^{2}$ Engineering Research Center of Artificial Organs and Materials, Ministry of Education, 510630 Guangzhou, China
}

Received 6 October 2013; accepted in revised form 23 December 2013

\begin{abstract}
The aim of the present work is to assemble extracellular matrix components onto poly (L-lactic acid) (PLLA) films using layer-by-layer (LBL) depositing method to enhance the cell-material interaction. To introduce charges onto the hydrophobic and neutral PLLA surface so that the electronic assembly can be processed, poly (ethylene imine) (PEI) was covalently bonded to modify the PLLA films. Positively charged collagen I (Col I) was then deposited onto the aminolyzed PLLA film surface in a LBL assembly manner using hyaluronic acid (HA) as a negatively charged polyelectrolyte. The PEI modification efficiency was monitored via X-ray photoelectron spectroscopy (XPS) measurements. The results of Surface Plasmon Resonance (SPR) and Water contact angle (WCA) monitoring the LBL assemble process presented that the HA/Col I deposited alternately onto the PLLA surface. The surface topography of the films was observed by Atomic force microscope (AFM). In vitro osteoblast culture found that the presence of Col I layer greatly improved the cytocompatibility of the PLLA films in terms of cell viability, cell proliferation and Alkaline Phosphatase (ALP) expression. Furthermore, osteoblast extensions were found to be directed by contact guidance of the aligned Col I fibrils. Thus, these very flexible systems may allow broad applications for improve the bioactivity of polymeric materials, which might be a potential application for bone tissue engineering.
\end{abstract}

Keywords: biocompatible polymers, layer by layer, type I collagen, hyaluronic acid, osteoblast

\section{Introduction}

Specially designed three-dimensional biomaterials provide one of the fundamental tools to shape and guide the tissue development in vitro and in vivo. Modern biomaterials for tissue-engineering applications must possess excellent biocompatibility, easily processed to have a variety of configurations, mechanical strength that needed for the creation of macroporous scaffold that will retain its structure after implantation as well as appropriate biodegradability. They should also provide the necessary physical and chemical cues to guide cell attachment, growth and differentiation to finally obtain a three-dimensional tissue $[1,2]$ in which surfaces play an important role in a biological system for most bio- logical reactions occurring at surfaces and interfaces [3]. Thus, the development of biomaterials for tissue engineering is to design a material with relatively high mechanical strength and create perfect surfaces which can provoke specific cellular responses and direct new tissue regeneration. However, few scaffolds can fit all of these qualifications. Among the variety of biomaterials used in the biomedical field, poly (L-lactic acid) (PLLA) is one of the polymers most widely employed for the regeneration of different tissues or organs, like bone [4, 5], cartilage [6] and skin [7], because of its relatively good mechanical and manufacturing properties. However, the biomedical applications of PLLA are hampered to a certain extent by its high hydro-

\footnotetext{
$\overline{{ }^{*} \text { Corresponding author, e-mail: tlihuali@jnu.edu.cn }}$

(C) BME-PT
} 
phobicity and lack of physiological activity $[8,9]$. It has been shown in a number of studies that PLLA does not provide a favorable surface for cell attachment and proliferation due to lack of specific cellrecognition signals [10]. Since implants and tissueengineering scaffolds interact with the biological environment via their surface, modification of the outermost part of materials may be sufficient to tailor its biocompatibility, while the bulk properties of the material are maintained [11]. However, the high hydrophobicity of PLLA material has made it difficult to get a stable biomimetic coating of hydrophilic natural biomacromolecules, and the lack of reactive side-chain groups to covalent cell-recognition molecules to PLLA molecules has limited its further application in tissue engineering and other biomedical areas. Though different strategies have been proposed [12, 13] like coating [14], plasma treatment [15], and entrapment [16], very few examples have considered assembling homogenously extracellular matrix components onto the PLLA film or scaffold. Therefore, how to introduce functional groups or molecules to polyester surfaces, which ideally adjust cell/tissue biological functions, becomes more and more important.

In nature, the biological world is built up via precise self-assembly of biomacromolecules. It provided a great inspiration for researchers to explore an engineered scaffold via macromolecules self-assembly $[17,18]$. Layer-by-layer (LBL) electrostatic selfassembly (ESA) of polyelectrolytes constitutes a novel and promising technique to modify surfaces in a controlled way $[19,20]$. This technique allows the build-up of thin films simply by the alternating deposition of polyanions and polycations to modify polymer surface and reconstruct ECM environment on biopolymer surface [21,22]. The ideal cell-carrier scaffold should probably mimic the naturally occurring environment in the cell matrix, for bone which is composed of collagen, especially type I, proteoglycans and hydroxyapatite. These biomacromolecules form physically or chemically crosslinked networks, regulating the expression of phenotype of the osteoblast and supporting osteogenesis both in vitro and in vivo $[23,24]$. Therefore, many natural extracellular matrixes (ECM)-like macromolecules, such as hyaluronic acid (HA) or collagen, have been incorporated into the 3-D scaffolds for bone regeneration [24-26].
Herein we describe the assembly of ECM components onto the biodegradable PLLA using LBL assembly technique to enhance the cell-material interaction after PEI modification. HA and Col I were chosen as the building blocks to build biomimetic layers on the PLLA films. Col I, an important ECM component of native bone tissue, has been verified as possessing osteoprotective ability [24, 25]. Moreover, it is positively charged in solution below isoelectric point [26], which allows Col I to be used as a polycation in a LBL assembly system, on which various polyanions can be adsorbed. In addition, HA is a major component of the extracellular matrix and of the synovial fluid, is also a negatively charged polyelectrolyte which has been used widely in a LBL assembly system [26, 27]. Therefore, Col I and HA were chosen as the polymer combination because of both the cytocompatibility and the layer stability in culture medium $(\mathrm{pH}$ 7.4) [26]. This work concerns the construction of assembly films with HA and Col I on the PEI modified PLLA film surface via LBL deposition. The culture of osteoblast in vitro showed that the cytocompatibility of the modified PLLA was improved obviously. In addition, osteoblast cells spread well in an aligned morphology and higher ALP expression only on the Col I terminated films. Therefore the ability to construct ECM-based films on PLLA may be a potential application for bone tissue engineering.

\section{Materials and methods \\ 2.1. Materials}

Poly-L-Lactide (PLLA, P), $\left(M_{\mathrm{W}} 100,000\right.$ with a viscosity of $2.3 \mathrm{dL} / \mathrm{g}$ ) was obtained from Shandong Institute of Medical Instruments, China. Hyaluronic acid (HA, H, $1000 \mathrm{kDa}$ ) was obtained from Shandong Freda Bio-Chemical Co., Ltd, China. Poly (ethylene imine) (PEI, P) $\left(M_{\mathrm{W}} 250000 \mathrm{~g} / \mathrm{mol}\right)$ was from Sigma, St. Louis, MO. N-(3 Dimethylaminopropyl)N'-ethylcarbod- imide hydrochloride (EDAC) and NHydroxy-Succinimidr (NHS) were obtained from Aldrich, China. High glucose DMEM and fetal calf serum were from Hyclone, China. 0.25\% trypsinEDTA was purchased from GIBCO, China. Osteoblast was supplied by Guangzhou First Affiliated Hospital of Jinan University. All other chemicals and reagents used were of analytical grade. 


\subsection{Extraction and purification of collagen type I}

Tail tendons were obtained from adult white rats. After pre-treated with $75 \%$ ethanol for $30 \mathrm{~min}$, rat tail tendons were kept in $0.05 \mathrm{M}$ Tris- $\mathrm{HCl}$ buffer ( $\mathrm{pH}=7.5$ ) for overnight. Then the chopped tendons were transferred and partially dissolved in $0.5 \mathrm{M}$ acetic acid (HAc) for 3 days. Pepsin was then introduced into the above solution at a ratio of 10:1 (w/v) and kept stirring for another 5 days under $4^{\circ} \mathrm{C}$. The obtained solution was filtered with cloth to remove the insoluble impurities and then precipitated out using $0.7 \mathrm{M}$ sodium chloride $(\mathrm{NaCl})$; under acidic conditions, this concentration of $\mathrm{NaCl}$ has been shown to precipitate collagen types I-IV [28]. The collagen protein was collected via filtration and redissolved in 0.5 M HAc, followed by thorough dialysis against $0.5 \mathrm{M} \mathrm{HAc}$. The final dry products were obtained by freeze-drying.

\subsection{Fabrication of PLLA films}

PLLA powder was dissolved in dichloromethane with magnetic stirring to obtain a homogenous $1.5 \mathrm{wt} \%$ solution, and then kept still for 10 minutes to remove the bubbles. Afterwards the solution was cast into a glass culture dish in a fume hood at room temperature. Plastic wrap was introduced to cover the dish to prevent fast evaporation of the solvent. After evaporation of the solvent, the translucent PLLA films with the thickness of $5 \mu \mathrm{m}$ were taken out from the dish and cut into discs with the diameter of $14 \mathrm{~mm}$.

\subsection{Surface modification of PLLA with PEI}

The two-step activation method was used for surface functionalization of PLLA, which has been described previously [29] and with some modification. Briefly, PLLA films were kept in $0.1 \mathrm{M} \mathrm{NaOH}$ for $20 \mathrm{~min}$ and then washed by distilled water and immersed in ethanol/water $(1: 1, \mathrm{v} / \mathrm{v})$ at room temperature for $30 \mathrm{~min}$ to clean organic residue. After washing, the PLLA films were transferred into EDC and NHS ( 3 and $5 \mathrm{mg} / \mathrm{mL}$, respectively, $\mathrm{pH}=6.0$ ) aqueous solution for $30 \mathrm{~min}$ under constant shaking. After rinsing with a large amount of water, films were dipped in $10 \mathrm{mg} / \mathrm{mL}$ PEI ( $\mathrm{pH}$ 7.4) solution and kept shaking for $5 \mathrm{~h}$ at $40^{\circ} \mathrm{C}$ before being cleaned and dried.

\subsection{Surface snalysis of PEI-modified PLLA}

The surface chemical composition of PLLA film before and after PEI treatment was investigated by X-ray Photoelectron Spectroscopy (XPS). XPS spectra of the samples were acquired on an ESCALAB 250 XPS spectrometer. High resolution spectra of $\mathrm{C} 1 \mathrm{~s}, \mathrm{O} 1 \mathrm{~s}$, and N1s peaks were also recorded and used to quantify the chemical composition of polar groups on the surface of the PEI-treated films by deconvolution and curve-fitting of the peaks.

\subsection{Build up of the polyelectrolyte multilayered films (PEMs)}

Col I $(5 \mathrm{mg} / \mathrm{mL}$ in $0.2 \mathrm{M}$ acetic acid) and HA $(5 \mathrm{mg} / \mathrm{mL}$ in MilliQ water) were used for Zeta potential measurement, which was determined with a Zetasizer Nano-Zs. Before each measurement, stored $\mathrm{Col} \mathrm{I}$ and HA solution were adjusted to different $\mathrm{pH}$ value in Hepes- $\mathrm{NaOH}$ buffer $(\mathrm{pH}=6.5)$. Measurements were carried out in triplicate at $25^{\circ} \mathrm{C}$ on three independent preparations. According to the Zeta potential results (Table 1) we chose $\mathrm{pH}=5$ as the working solution, as Col I easily forms fibers in a relative high $\mathrm{pH}$ value [30]. Then the LBL assembly processes were carried out as the following steps (the schematic illustration was shown in Figure 1).

Table 1. Zeta potential of $\mathrm{Col} \mathrm{I}$ and $\mathrm{HA}$ under $\mathrm{pH}=5$; results are the means $\pm \mathrm{SD}$ of three independent experiments

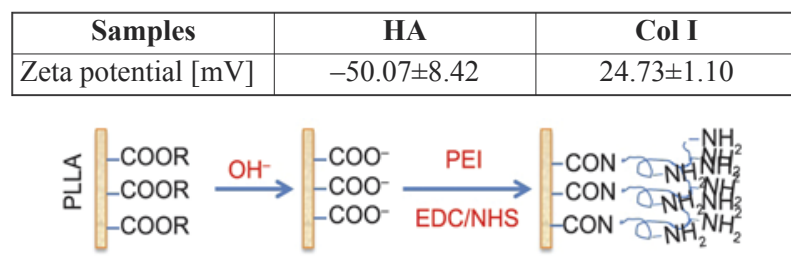

a)

PEI aminolysis of PLLA

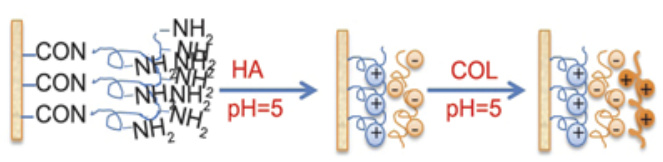

b)

LBLassembly on PLLA

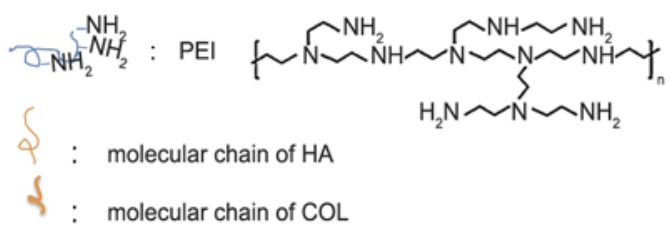

Figure 1. Schematic illustration of the surface modification strategy of PLLA, a) PEI modification of PLLA, b) build-up of polyelectrolyte multilayer 
First, the films were immersed into $\mathrm{HA}(1 \mathrm{mg} / \mathrm{mL}$ in MilliQ water, $\mathrm{pH}=5$ ) aqueous solution for $15 \mathrm{~min}$ following with MilliQ water $(\mathrm{pH}=5)$ washing. Then, the films were placed into the Col I solution $(1 \mathrm{mg} / \mathrm{mL}$ in $0.2 \mathrm{M} \mathrm{Hac}, \mathrm{pH}=5$ ) for $20 \mathrm{~min}$, following by MilliQ water $(\mathrm{pH}=5)$ washing in a row. By repeating those steps, multilayers were built up to 10 and 11 layers, which abbreviated as $\mathrm{PP}(\mathrm{HC})_{5}$ (PLLA substrate modified with PEI plus 5 bilayers of HA and $\mathrm{Col} \mathrm{I}$ ) and $\mathrm{PP}(\mathrm{HC})_{5} \mathrm{H}$ (PLLA substrate modified with PEI plus 5 bilayers of HA and Col I plus HA); the PLLA film and PLLA film modified with PEI were abbreviated as $\mathrm{P}$ and $\mathrm{PP}$ respectively. Finally, the films were dried with flow of nitrogen.

\subsection{Characterization of PEM formation by surface plasmon resonance (SPR) and water contact angle (WCA) measurements}

The construction process of the PEM was monitored by SPR (IBIS Technologies B.V.) and static WCA measurements. SPR is based on the detection of changes in the refractive index (RI) at the goldliquid interface of the SPR gold sensor surface caused by the adsorption of molecules. The resulting change in the SPR angle shift $\left[\mathrm{m}^{\circ}\right]$ is proportional to the mass $(\Gamma)$ of adsorbed molecules on the surface as shown by Equation (1) [31]:

$$
122 \mathrm{~m}^{\circ} \approx 1 \mathrm{ng} / \mathrm{mm}^{2}(\Gamma)
$$

Hence, subsequent adsorption of layers should lead to a step-wise change in angle shift, which demonstrates multilayer formation. To detect PEM formation, the sensor used here was spin-coated with an ultrathin layer of PLLA at first. After chemical modification with PEI as described above, the sensor was mounted on the prism. Shift in resonance angles from 10 regions of interest defined on the sensor surface were recorded using the SPR software. LBL assembly on PEI-modified sensor was not started until a stable basal curve was obtained. HA solution was flowing over the sensor surface for $15 \mathrm{~min}$, then MilliQ water $(\mathrm{pH}=5)$ was used to rinse for $3 \times 5$ min times. Col I solution was used for another 20 min before rinsed again with MilliQ water $(\mathrm{pH}=$ 5 ). This process was repeated several times. The assembly process was monitored in-situ by angular scan mode; the averaged value of angle shift was given by the software of the device.
WCA measurement was performed using a sessile drop method with an OCR 15 plus device from Dataphysics, (Filderstadt, Germany). Water drops with a volume of $1 \mu \mathrm{L}$ were placed onto the sample which was fixed on a cover slide with double-side tape. 5Point measurements once a water droplet contacted the sample surface for 15 seconds were performed at positions selected randomly. Thereafter, the contact angles were determined with specific software and the average value of the 5-point measurements was regarded as the contact angle of the samples.

\subsection{Atomic force microscopy (AFM) analysis}

The surface morphology of the PLLA films was obtained by AFM in the tapping mode. AFM measurements were performed in ambient conditions at room temperature using an Auto Probe CP Research AFM (Thermo Microscopes Inc., Sunnyvale, CA, precently named Veeco Instruments). Images were scanned using a tip with typical spring constant of $3 \mathrm{~N} / \mathrm{m}$, a resonant frequency of $\sim 80 \mathrm{kHz}$ (MPP21123 , Veeco Instruments). The scan area was $5 \times 5$ and $2 \times 2 \mu \mathrm{m}$ respectively. Image processing and data analysis were performed using Proscan Image Processing Software Version 2.1 provided with the instrument.

\subsection{Osteoblast culture}

Osteoblast isolated from the skull of 1-2 day newly born SD rat was used for cell culture experiments in vitro. The cells were grown in culture petri dishes $(100 \mathrm{~mm})$ with high-glucose DMEM medium supplemented with $10 \%(\mathrm{v} / \mathrm{v})$ fetal bovine serum (FBS). Cell culture was maintained in an incubator equilibrated with $5 \% \mathrm{CO}_{2}$ at $37^{\circ} \mathrm{C}$. Cells after almost confluent were washed once with sterile PBS and followed by treatment with $0.25 \%(\mathrm{w} / \mathrm{v})$ EDTAtrypsin for $5 \mathrm{~min}$ at $37^{\circ} \mathrm{C}$. Cells were harvested and resuspended in culture medium after centrigugation for $5 \mathrm{~min}$ at $1000 \mathrm{r} / \mathrm{min}$. Before cell seeding, the $\mathrm{P}$, $\mathrm{PP}, \mathrm{PP}(\mathrm{HC})_{5}$ and $\mathrm{PP}(\mathrm{HC})_{5} \mathrm{H}$ films were placed into the 24 well tissue culture plates (TCPS, 24 Well) and sterilized by $75 \%$ ethanol and then were incubated in PBS for 1 day to exchange the ethanol and further were exchanged with cell culture medium overnight. Next, $1 \mathrm{~mL}$ of osteoblast suspension $\left(2.5 \cdot 10^{4}\right.$ cells $\left./ \mathrm{mL}\right)$ was dropped directly onto the surface of the films. Media was changed every two days during this experiment. 


\subsection{Cell viability and proliferation}

The control and the modified P films were placed on the bottom of TCPS. Live/dead staining was carried out to evaluate cell viability using Calcein-AM (live cell: green) and Propidium Iodide (dead cell: red) staining reagents kit (abcam, Hongkong) at 3 and 5 days with a seeding density of $2.5 \cdot 10^{4}$ cells/well. The cell viability was calculated according to Equation (2) $(n=3)$ :

$$
\text { Cell viability }=\frac{\text { number of green-stained cell }}{\text { number of green-stained cell }+ \text { number of red-stained cell }}
$$

Where the green-stained cells presented live cells and the red-stained cells represent dead cells. The cell proliferation ratio was assessed by MTT (3-(4, 5-dimethylthiazol-2-yl)-2, 5-diphenyl tetrazolium bromide) assay. After incubated for 2,4 , and 6 days with a seeding density of $2.5 \cdot 10^{4}$ cells/well, $20 \mu \mathrm{L}$ MTT solution was added to each well and then incubated at $37^{\circ} \mathrm{C}$ for $4 \mathrm{~h}$. Thereafter, $200 \mu \mathrm{L}$ dimethylsulfoxide (DMSO) was added after supernatant medium was removed and the absorbency value (OD value) was recorded at a wave length of $490 \mathrm{~nm}$.

\subsection{Cell distribution and morphology observation}

To observe the morphology of the osteoblast, the samples were transferred into new 24 well plates, rinsed three times with PBS ( $5 \mathrm{~min} / \mathrm{times}$ ), and followed by fixing with $2.5 \%$ glutaraldehyde (GA) at $4{ }^{\circ} \mathrm{C}$ for $30 \mathrm{~min}$. After thoroughly rinsing with PBS, samples were gradiently dehydrated by ethanol and freeze-dried. Thereafter, samples were coated with gold for SEM observation.

To further observe the cell cytoskeleton distribution under laser confocal scanning microscope (CLSM), the cell-films constructs were taken out from the well plate and fixed for $15 \mathrm{~min}$ with $3.7 \%$ formaldehyde in PBS. After properply rinsed with PBS, the cells were permeabilized with $0.5 \%(\mathrm{v} / \mathrm{v}$ in PBS) Triton $\mathrm{X}-100$ for another $15 \mathrm{~min}$. After rinsing twice again with PBS the non-specific binding sites were blocked by incubation with $3 \%$ non-fat dry milk in PBS at $4^{\circ} \mathrm{C}$ for 1 hour. Filamentous actin was stained by incubatation with rhodamine-conjugated phalloidin (Biotium, USA) for $30 \mathrm{~min}$ in darkness at room temperature. Samples were followed by incubation with DAPI (Invitorgen, USA) for $10 \mathrm{~min}$ at $37^{\circ} \mathrm{Cto}$ visualize the Nuclei.

\subsection{Alkaline phosphatase (ALP) activity test}

ALP is known to be associated with bone metabolism and differentiation of osteoblasts. To assay for ALP activity, cells were cultured on films for 7 and 14 days at an initial seeding density of $2.5 \cdot 10^{4}$ cells/well. At harvest, cell layers were washed with PBS and a volume of $200 \mu \mathrm{L}$ of $0.2 \%$ Triton $\mathrm{X}-100$ was added to each well to study the lysis of cells. The total intracellular protein content in the cell lysates was measured spectrophotometrically using a BCA protein assay (Nanjing Jiancheng Bioengineering Institute, China) according to the manufacturer's instructions. ALP activity was assayed as the release of p-nitrophenol from p-nitrophenyl phosphate using a commercial kit (Nanjing Jiancheng Bioengineering Institute, China). Aliquots of the same solutions used for calculating total protein content were assayed for measuring ALP activity. Results were expressed as ALP activity (U/gprot) normalized by the total protein content.

\subsection{Statistics}

All data are represented as mean values \pm standard deviations (SD). Statistical analysis was performed using origin with ANOVA test (One way). The number of samples has been indicated in the figures and table captions. Statistical significance was considered for $\mathrm{P}<0.05(*), \mathrm{P}<0.01(* *)$ and $\mathrm{P}<0.01(* * *)$.

\section{Results and discussion}

\subsection{X-ray photoelectron spectroscopy (XPS)}

XPS is an effective method to characterize the chemical composition of surfaces. For plain PLLA (Figure 2a), two peaks appeared in the XPS survey spectrum, which could be assigned to the elements carbon and oxygen. After PEI modification (Figure $2 b$ ), a new nitrogen peak emerged. The quantities of different elements for the PLLA modifica- 
a)

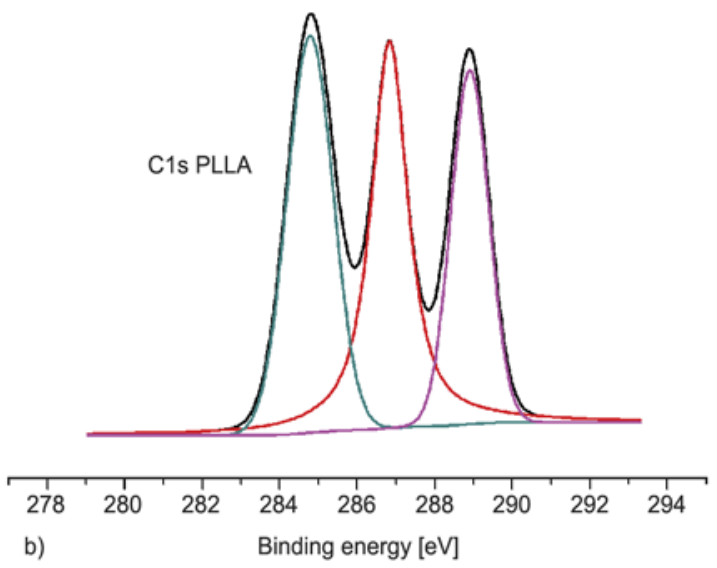

b)

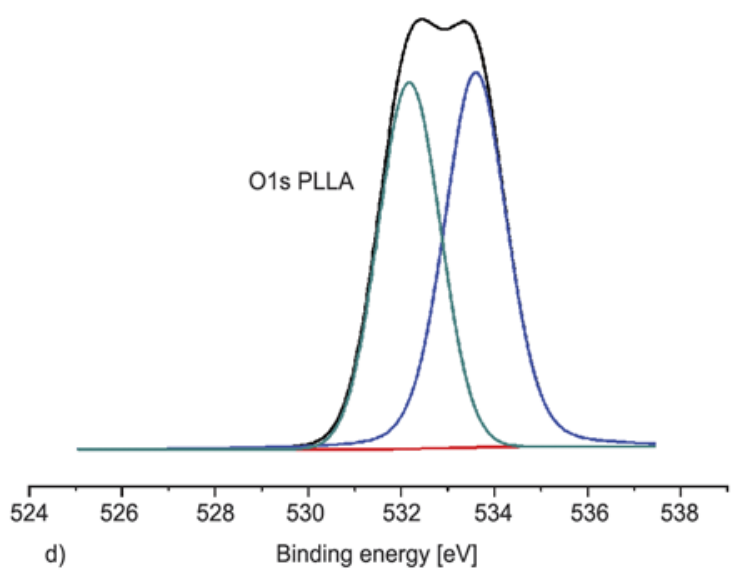

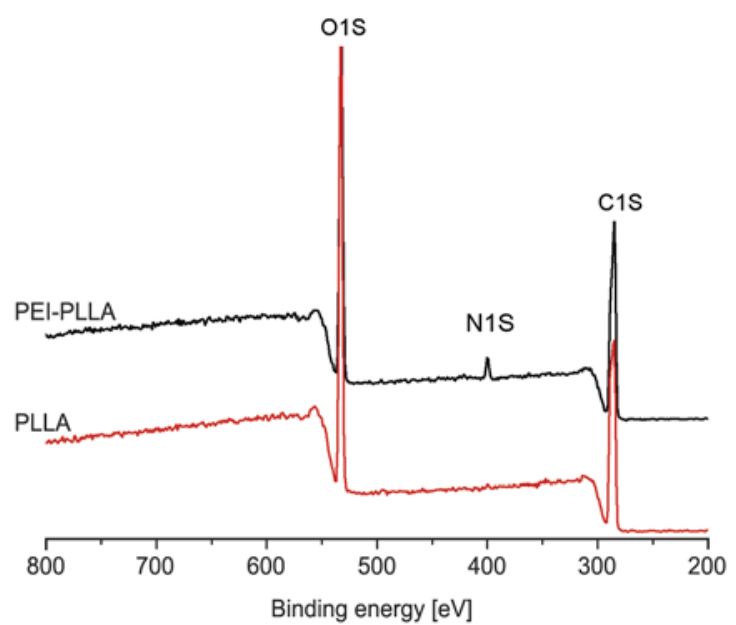
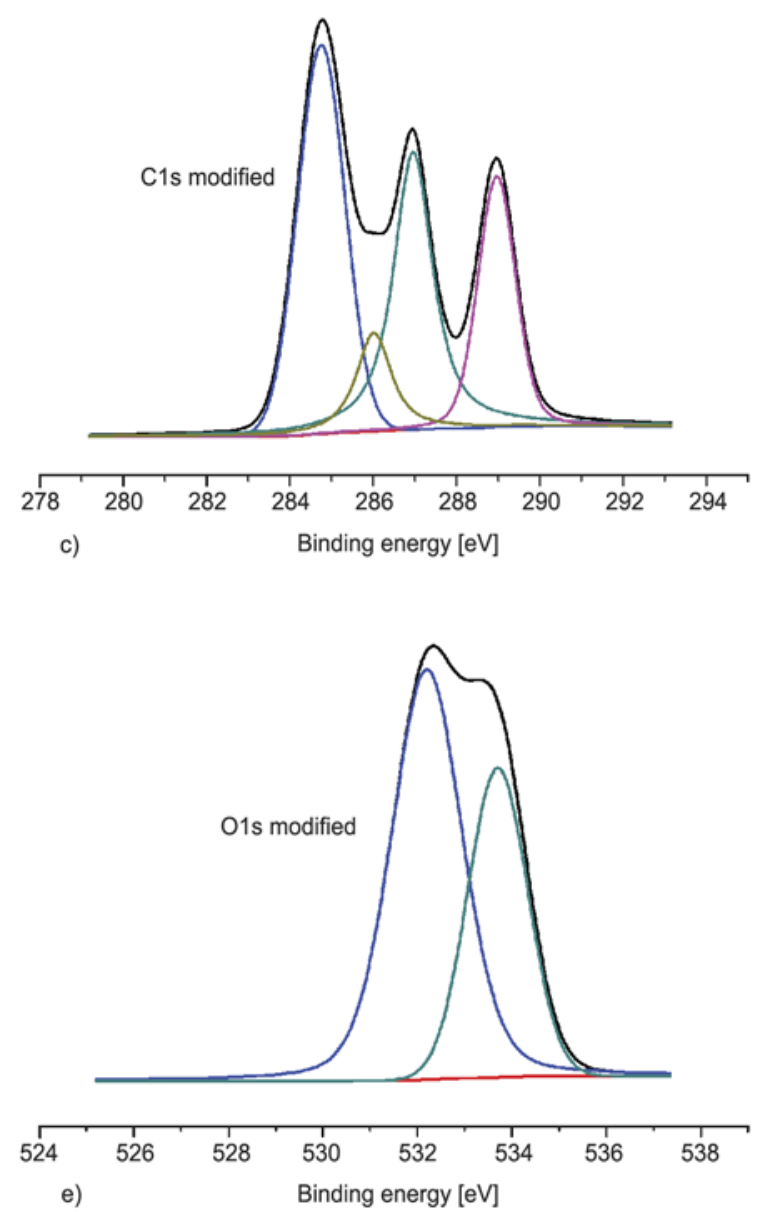

Figure 2. XPS survey spectra for different PLLA surfaces and fitting analysis of the $\mathrm{C} 1 \mathrm{~s}$ and $\mathrm{O} 1 \mathrm{~s}$ spectra to quantify the different functional groups at the surface of plain PLLA and PEI-PLLA, a) XPS survey spectra of different PLLA surfaces, b) C1s spectra of PLLA, c) C1s spectra of PEI-PLLA, d) O1s spectra of PLLA, e) O1s spectra of PEI-PLLA

Table 2. Atomic percentages on the surface of different PLLA samples obtained from the XPS measurements

\begin{tabular}{|l|c|c|c|}
\hline \multicolumn{1}{|c|}{ Sample } & $\begin{array}{c}\text { C } \\
{[\mathbf{\%}]}\end{array}$ & $\begin{array}{c}\mathbf{N} \\
{[\mathbf{\%}]}\end{array}$ & $\begin{array}{c}\mathbf{O} \\
{[\mathbf{\%}]}\end{array}$ \\
\hline $\mathrm{P}$ & 58.18 & 0.17 & 41.58 \\
\hline $\mathrm{PP}$ & 60.16 & 2.85 & 36.27 \\
\hline
\end{tabular}

tion are listed in Table 2. These data are a further proof for immobilization of PEI onto PLLA films. Curve-fittings of high-resolution spectra for the different elements on blank and PEI-modified PLLA surface are shown in Figure 2. For C1s core level spectrum, PLLA contains three peaks at binding energy (BE) of 284.78, 286.83, and $288.91 \mathrm{eV}$, 
which was attributed to the $\mathrm{C}-\mathrm{H}, \mathrm{C}-\mathrm{H}_{2}$ or $\mathrm{C}-\mathrm{H}_{3}$ binding, $\mathrm{C}-\mathrm{O}$ and $\mathrm{C}=\mathrm{O}$ or $\mathrm{COOH}$ groups respectively, in correspondce well with the chemical structure of PLLA. After modification by PEI, a new type of carbon bond, attributed to the $\mathrm{C}-\mathrm{N}$ binding appeared, it can be ascribed to covalent binding from PEI amino groups to carboxylic groups of PLLA.

For O1s core-level spectra, there are two types of oxygen bonds on blank PLLA, which was ascribed to $-\mathrm{C}-\mathrm{O}-\mathrm{C}-$ or $\mathrm{C}=\mathrm{O}$ bonds. After the chemical reaction between the carboxylic groups and the amino groups, the content of $\mathrm{C}=\mathrm{O}$ bond decreased due to replacement by the amide bond, which is confirmed in Figure 2.

\subsection{Multilayer formation}

To assemble extracellular matrix components onto the surface of PLLA film to improve its cell affinity, HA and Col I are used as the building blocks to cover the PLLA films with a multilayer thin coating. The $\mathrm{HA} / \mathrm{Col}$ I alternate deposition for individual layers on PLLA film was monitored in situ with the SPR. The SPR technology allows time-resolved monitoring of dynamic processes and is therefore also an attractive alternative method for ultrathin film characterization.

The adsorbed mass (Equation (1)) of polyelectrolytes after washing was presented by SPR measurement (Figure 3). The multilayer growth seemed to be linear in all cases. It must be pointed out here that the collagen deposition behaviour was some-

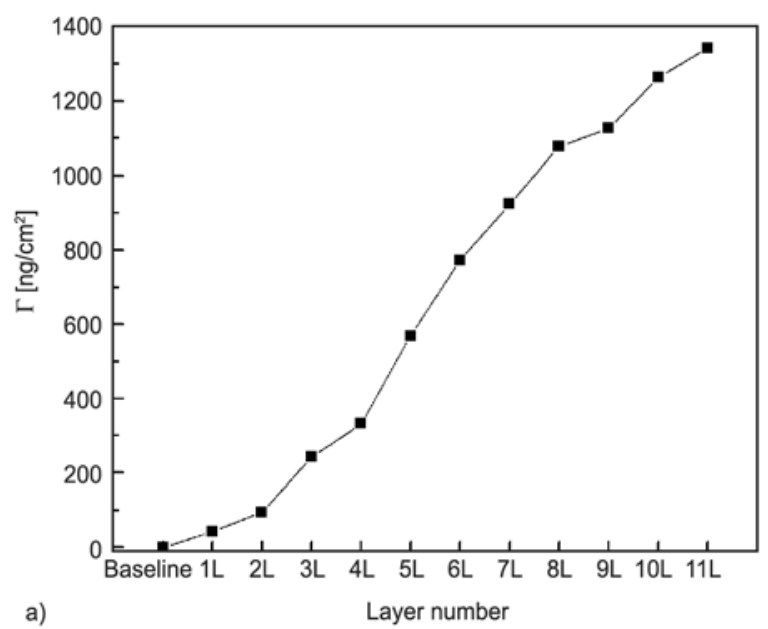

what different from that of HA. For HA, a slight increase was recorded immediately after the introduction of HA to the analytical chamber, due to the negative charged HA adsorbing on the aminolyzed positive charged PLLA film surface through electrostatic attraction. After washing a little increase indicates that there was a mass increase after the washing procedure, as the HA is known to be highly hydrophilic and is able to bind large amounts of water [32], so the mass increase may be due to the trap of water in HA. Similar trend was found in the Col I formation on the surface except that there is mass decrease after the washing step. Overall, it can be obviously observed in Figure 3 that the adsorbed mass increased dramatically with the layer deposition.

Static WCA measurements have been widely applied to determine the change of terminal layer composition during assembly of multilayers and were used here to study wettability after the deposition of each layer. Figure 3 presented that, after modification of PLLA with PEI, a slight drop in WCA value occurred. During the first modification step with HA, there is a drop occurred while after again the adsorption of Col I, a slight increase in WCA was appeared. Thereafter, a regular multilayer formation process was observed indicated by oscillation of WCA with a continuous drop. The alternating contact angles between HA and Col I layers contributed to the change in the composition of the terminating molecule layer. Since pure Col I films have been characterized as quite hydrophobic $\left(\mathrm{WCA} \approx 110^{\circ}\right.$ ) [33],

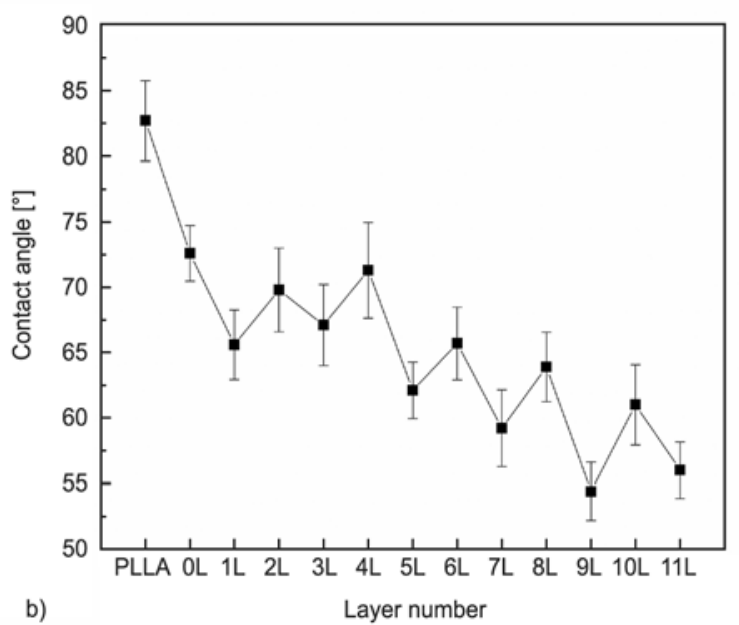

Figure 3. Accumulated mass during multilayer formation up to 11 layers calculated from SPR and changes of WCA during the multilayer formation). $(0-11 ; 0=$ poly (ethylene imine), all odd numbers $=$ HA and even numbers $=$ Col I). (The procession is based on the alternating adsorption of oppositely charged HA and Col I onto a positively charged pre-modified PLLA substrate), a) accumulated mass calculated from SPR, b) WCA value during the multilayer formation 
while HA as hydrophilic $\left(\mathrm{WCA} \approx 30^{\circ}\right.$ ) [34]. The difference in WCA between the layers indicated a dominance of either HA or Col I in the outer layers after the corresponding coating step. Overall, the change of the WCA indicated that the hydrophilicity of the PLLA surface was greatly increased by modification with the alternate deposition of $\mathrm{HA} / \mathrm{Col} \mathrm{I}$.

\subsection{Atomic force microscope (AFM)}

AFM measurement presented the surface morphology of the $\mathrm{P}(\mathrm{a}, \mathrm{b})$ and $\mathrm{PP}(\mathrm{HC})_{5}(\mathrm{c}, \mathrm{d})$ film as shown in Figure 4. Results showed that there was no significant feature on the surface of the PLLA film while after the alternate deposition of $\mathrm{HA} / \mathrm{Col} \mathrm{I}$, the topography displays large and long fibers whose width ranges from 100 to $120 \mathrm{~nm}$ and which were several micrometer long. These fibrils are tightly entangled into networks in a large scale (Figure 4c) while assembled to an aligned form in a relative small scale (Figure 4d). In vivo, collagen fibrils are
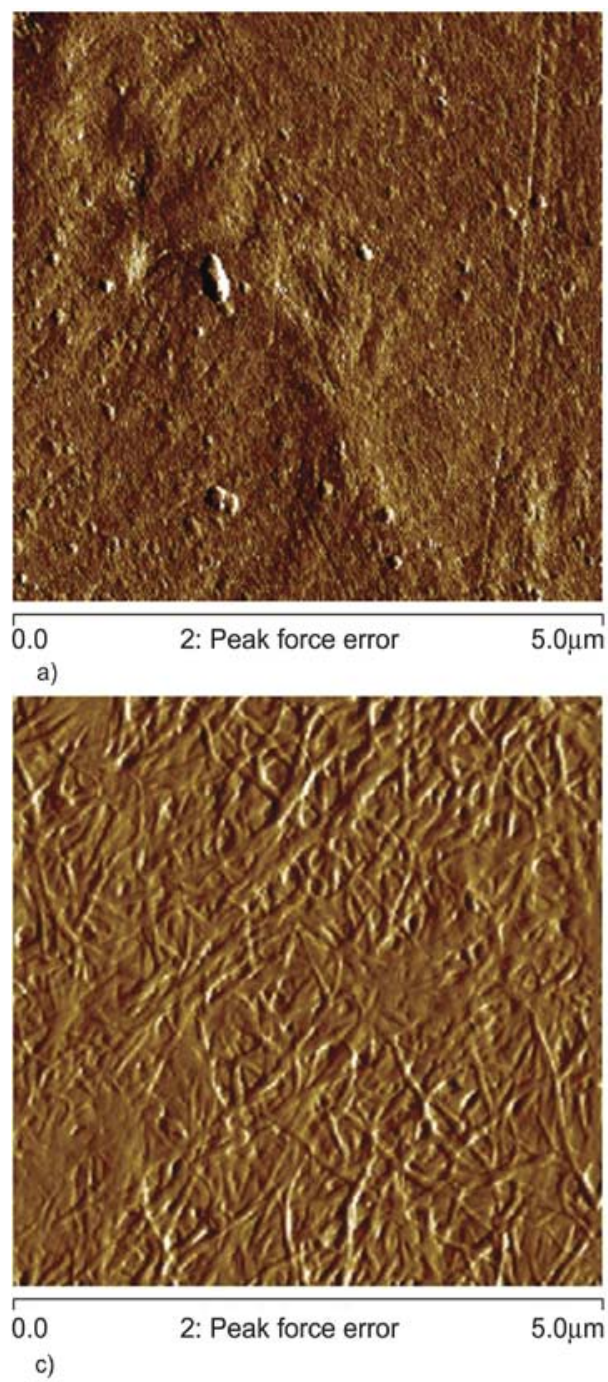

Figure 4. AFM image of the $\mathrm{P}(\mathrm{a}, \mathrm{b})$ and $\mathrm{PP}(\mathrm{HC})_{5}$ film (c, d) arranged in complex three-dimensional arrays, often in an aligned manner to fulfill certain biomechanical functions. This aligned collagen fibrils organization in vitro has proved to impact cellular function, including adhesion, orientation, proliferation and differentiation $[35,36]$.

\subsection{The cytocompatibility of the modified PLLA films}

The alternatively deposition of HA and Col I onto the PEI modified PLLA films provided the possibility of improving the film's cytocompatibility. Firstly, osteoblast culture was performed to assess the cell response to the modified PLLA films as a function of layer number. The results show that all the modified PLLA films could effectively increase the cell proliferation (Figure 5) and viability (Equation (2)) (Figure 6 and Table 3) compared with the control PLLA film. An overall improvement in the cellmaterial interaction was achieved when Col I sup-
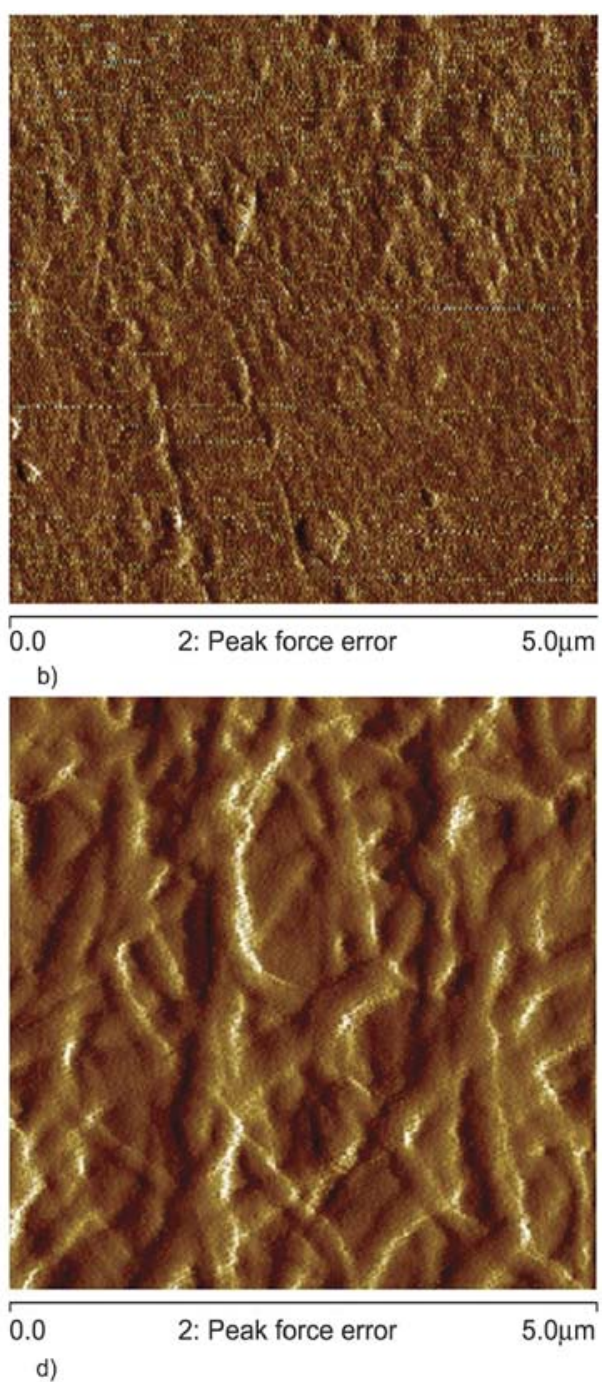


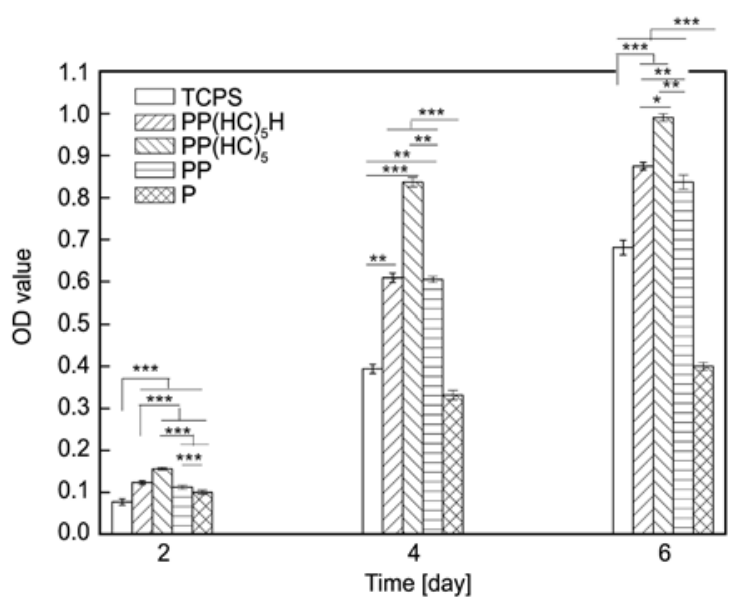

Figure 5. Cell viability (MTT assay) of osteoblasts cultured for 2, 4, 6 days respectively; results are the means $\pm \mathrm{SD}$ of three independent experiments, $[n=5, * \mathrm{P}<0.05, * * \mathrm{P}<0.01, * * * \mathrm{P}<0.001]$

Table 3. The viability of osteoblast cultured on different kinds of films for 3 and 5 days respectively [\%]; results are the means $\pm \mathrm{SD}$ of three independent experiments

\begin{tabular}{|l|c|c|}
\hline \multicolumn{1}{|c|}{ Samples } & 3 days & 5 days \\
\hline $\mathrm{P}$ & $66.78 \pm 4.76$ & $64.56 \pm 3.78$ \\
\hline $\mathrm{PP}$ & $76.47 \pm 5.41$ & $71.80 \pm 4.10$ \\
\hline $\mathrm{PP}(\mathrm{HC})_{5}$ & $96.45 \pm 3.87$ & $95.47 \pm 2.17$ \\
\hline $\mathrm{PP}(\mathrm{HC})_{5} \mathrm{H}$ & $81.21 \pm 3.90$ & $74.69 \pm 2.98$ \\
\hline
\end{tabular}

plied as the outermost layer. In particular, the cell proliferation ratios on the Col I terminated films were greatly improved, with values more than that of TCPS. The highest cell viability (shown in Table 2) also observedon the Col I terminated films. This could be attributed to the uniform Col I coating formation on the surface, a previous study found that Col I enhanced HOS proliferation [37]. Therefore the presence of native, fibrils structure of the Col I coating layer contributed significant to the improved cytocompatibility of the PLLA film.

\subsection{Cell morphology}

Scanning electron microscope (SEM, JSM26390LV) images after osteoblast cultured for 3 and 5 days were shown in Figure 7, some of the cells on the control PLLA (Figure 7d, 7h) film seemed to be shrinkage and detached from the substrate, and the cell number was also very small. On the other hand, the osteoblast on the $\mathrm{PP}(\mathrm{HC})_{5}$ (Figure7a, 7e), PP (Figure $7 \mathrm{c}, 7 \mathrm{~g}$ ) and $\mathrm{PP}(\mathrm{HC})_{5} \mathrm{H}$ (Figure $7 \mathrm{~b}, 7 \mathrm{f}$ ) films displayed flatten shapes and a spreading morphology on the substrate, while the forming of confluent and aligned cell layers during the observation time only achieved on the Col I terminated films. In addition, on the Col I terminated films, SEM micrographs of the cells showed cell projections and extensions. Those cell extensions seemed to be in a regular way, which might be created by the contact guidance of the Col I fibrils. In contrast, cells on other groups showed a randomly extension.

A similar conclusion could be made after observation by CLSM (Figure 8). Figure 8 shows that most of the osteoblasts on the control PLLA film spread not so well and seemed to shrink. In the other three groups, cells maintained their typical morphology, while the cellular morphology was different in different groups. Numerous well defined actin filaments were observed in PEI modified and HA ended samples, and interestingly, actin filaments extended in irregular directions in both groups, while more dense, spreading and aligned osteoblasts existed on the PLLA films covered with Col I as the outermost layer (Figure 8a). The actin filament distribution was fully spread in $\mathrm{PP}(\mathrm{HC})_{5}$ film (Figure 8a). Moreover, all of the actin filaments with regular directions in $\mathrm{PP}(\mathrm{HC})_{5}$ film were well-defined and the actin microfilament system ran parallel to the long axis of the cells while it ran in irregular directions in the other groups (Figure $8 \mathrm{~b}, 8 \mathrm{c}, 8 \mathrm{~d}$ ). This probably indicates weak cellular adhesion on other samples as compared to Col I ending ones. As well known, Col I is a structural protein present in the ECM and is extensively used to form scaffolds or films as promoter for cell adhesion, spreading and so on [36]. The natural structure of collagen fibers are proved to enhance cell attachment to synthetic surfaces [38] and it has been reported that fibroblasts align along oriented collagen fibril matrices via contact guidance $[39,40]$.

\subsection{Alkaline phosphatase (ALP activity)}

In accordance with expectations, the ALP level increased in all cultures. Cells cultured on the $\mathrm{PP}(\mathrm{HC})_{5}$ films presented highest activity of ALP than the other three groups at $7^{\text {th }}$ and $14^{\text {th }}$ day which was shown in Figure 9. However there were no significant differences between $\mathrm{PP}$ and $\mathrm{PP}(\mathrm{HC})_{5} \mathrm{H}$ groups. While the activity of ALP on the control PLLA film was the lowest among all the samples. It demonstrated that after the modification of the PLLA, especially with the Col I terminated films, the present of ALP was obviously improved. 


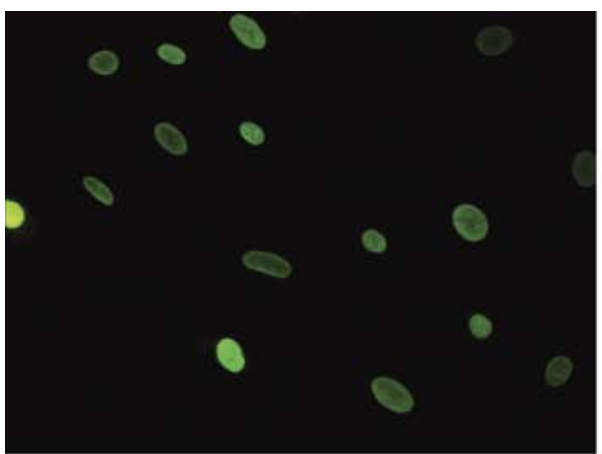

a)

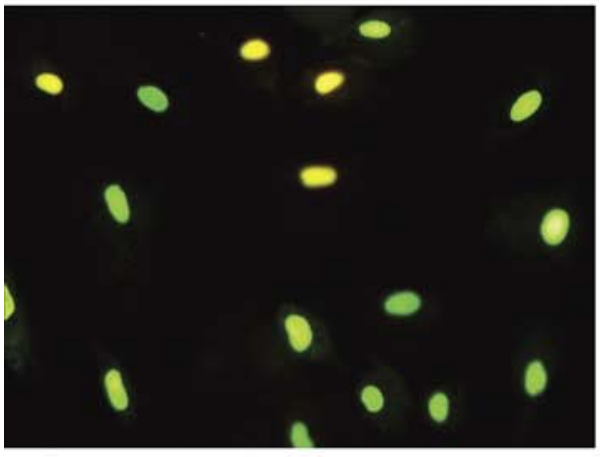

b)

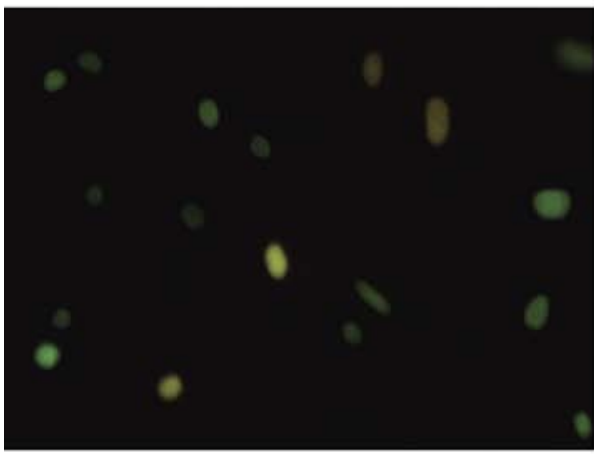

c)

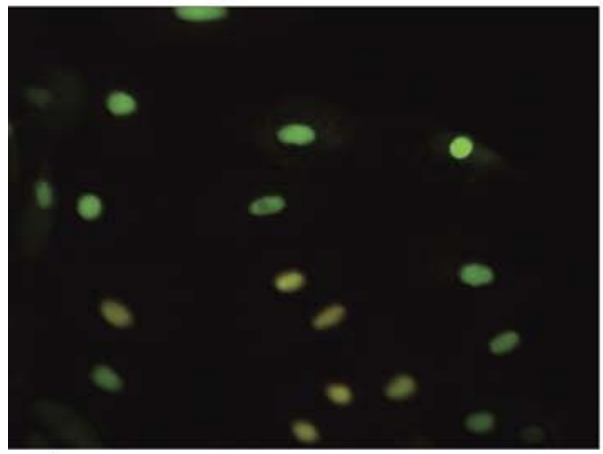

d)

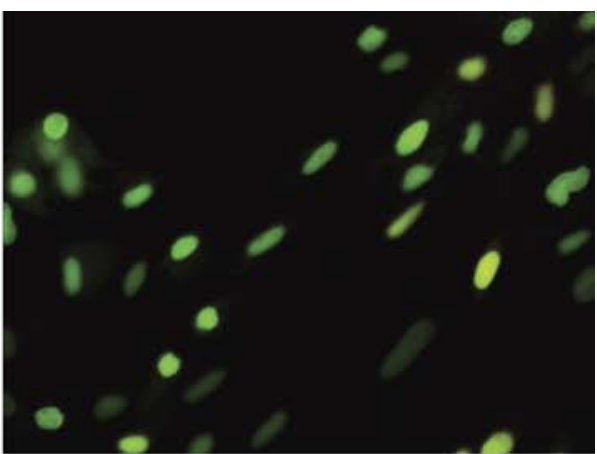

e)

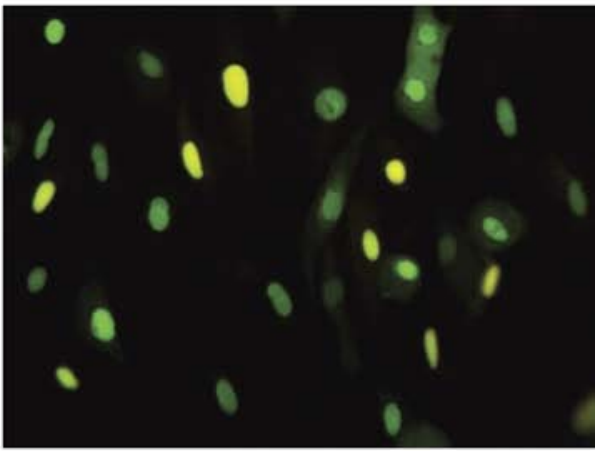

f)

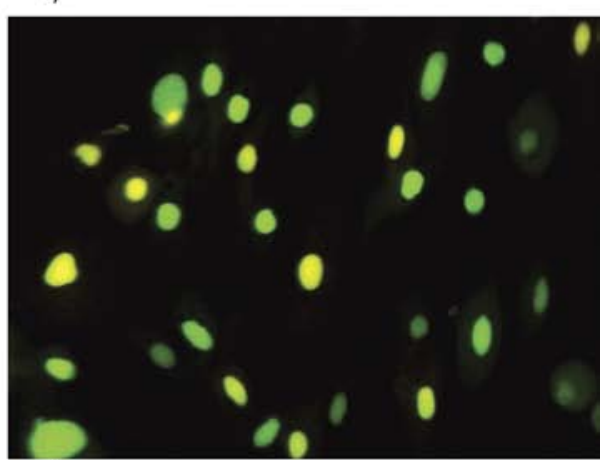

g)

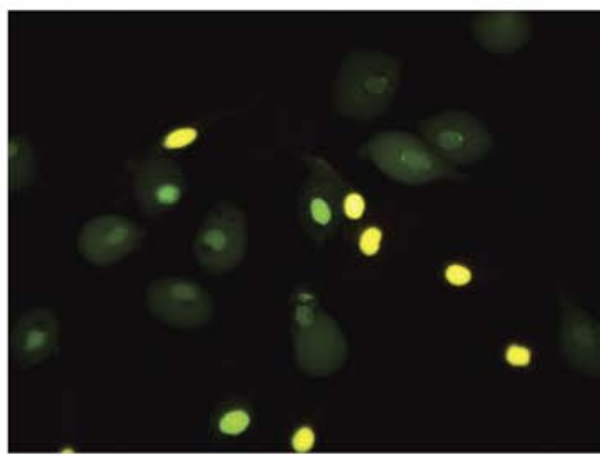

h)

Figure 6. Calcein-AM/PI live/dead staining of osteoblast on $\mathrm{PP}(\mathrm{HC})_{5}$ (a 3 days, e 5 days), $\mathrm{PP}(\mathrm{HC})_{5} \mathrm{H}$ (b 3 days, f 5 days), PP (c 3 days, g 5 days) and P (d 3 days, h 5 days) film respectively. Live cells stain green and dead cells stain red. (Original magnification $\times 200$ )

\section{Conclusions}

To improve the cell biocompatibility and cell affinity of PLLA films, the extracellular matrix components HA and Col I have been successfully deposited onto the PEI modified PLLA films using LBL assembly technique. The buildup of multilayer films exhibits a linear growth regime with the successive layer depositions, the Col I terminated samples leading to a uniform and relative aligned fibril network covering on the surface of the PLLA film. WCA 


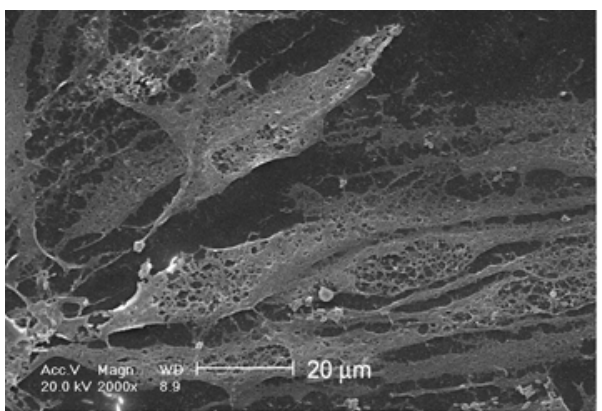

a)

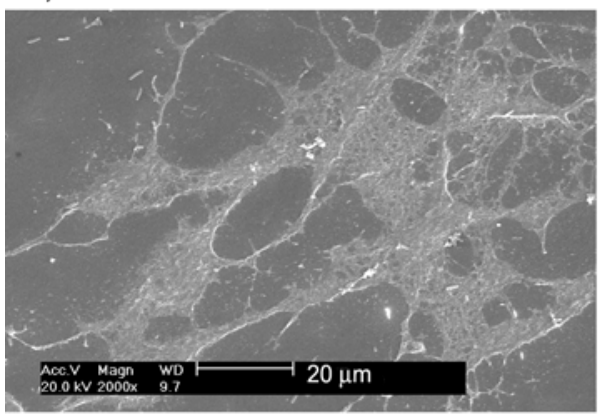

b)

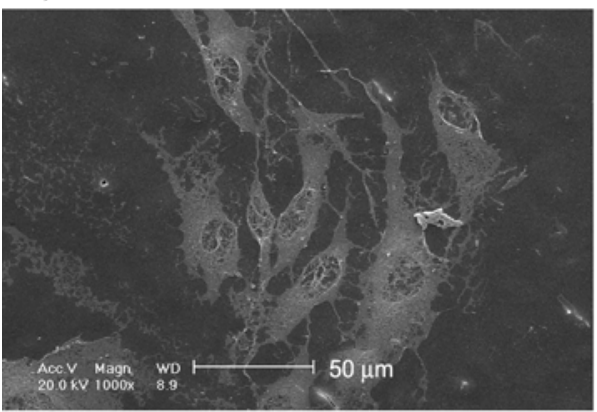

c)

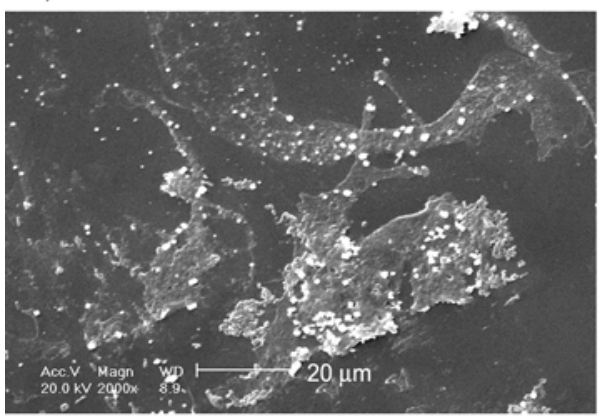

d)

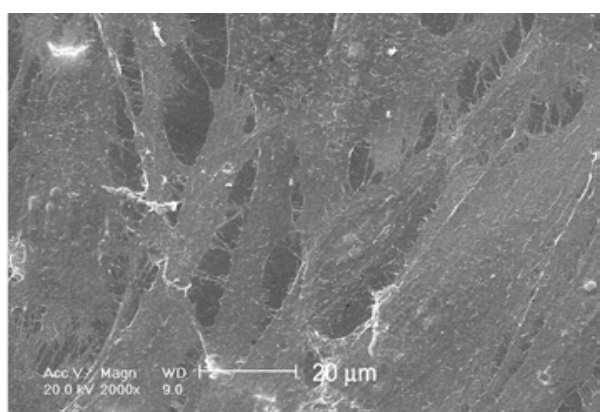

e)

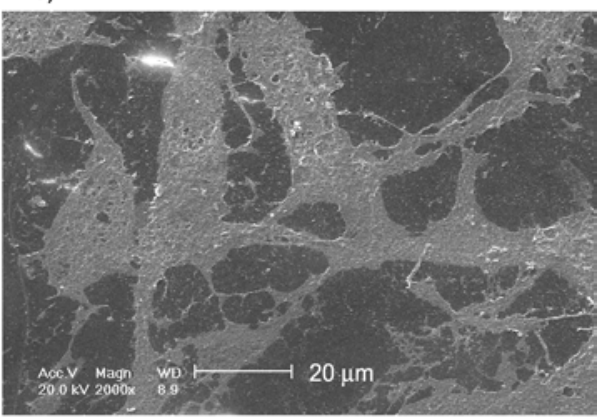

f)

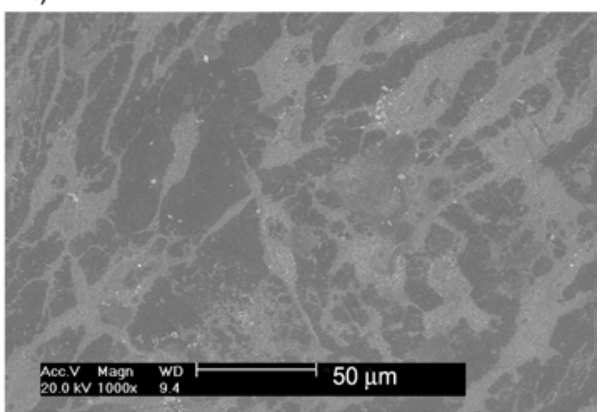

g)

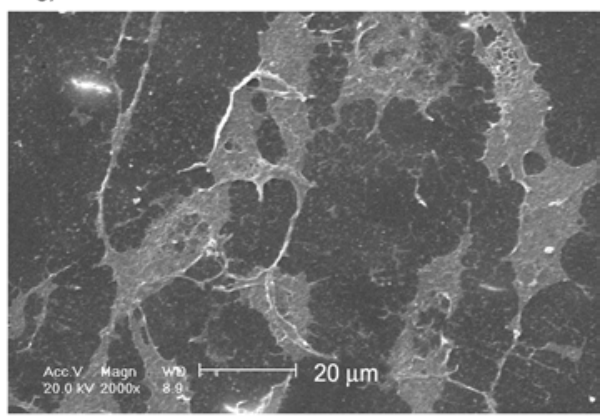

h)

Figure 7. SEM image of osteoblast morphology on $\mathrm{PP}(\mathrm{HC})_{5}(\mathrm{a}, \mathrm{e})$; $\mathrm{PP}(\mathrm{HC})_{5} \mathrm{H}(\mathrm{b}, \mathrm{f}) ; 0 \mathrm{~L}(\mathrm{c}, \mathrm{g})$; PLLA (d, h) film for 3 and 5 days respectively

results showed that after the LBL modification, the hydrophilicity of the film was dramatically enhanced. Cell viability and proliferation were apparently improved after LBL modification of the PLLA film. Moreover, cells presented highest viability, proliferation and ALP expression on the Col I terminated films, and osteoblast extensions were found to be directed by contact guidance of the aligned $\mathrm{Col} \mathrm{I}$ fibrils. This study further demonstrated that the coat- ing of ECM on to the organic PLLA film surface dramatically improved its cell compatibility. Comparing with conventional coating methods, polyelectrolyte multilayer is easy to prepare using LBL technique. Therefore, it may be an ideal choice to construct ECM-based films or 3D scaffolds for tissue engineering. Moreover, these very flexible systems may allow broad applications for improve the bioactivity of polymeric materials. 


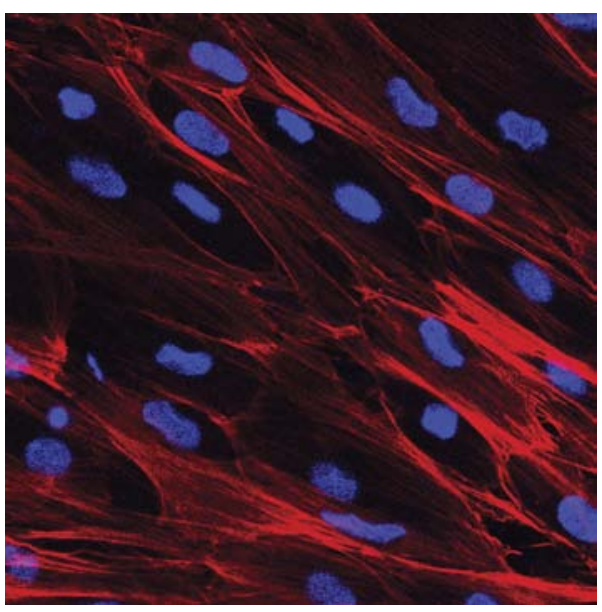

a)

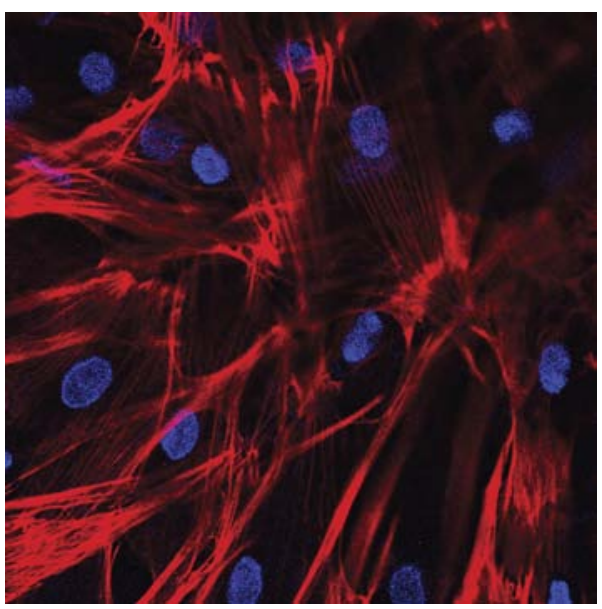

c)

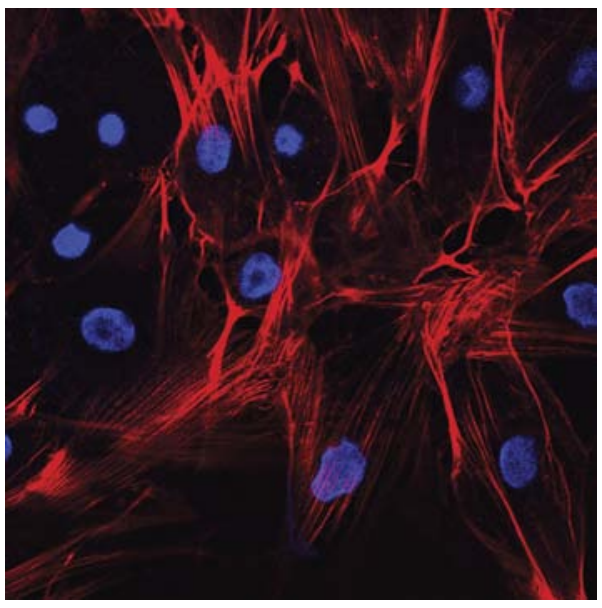

b)

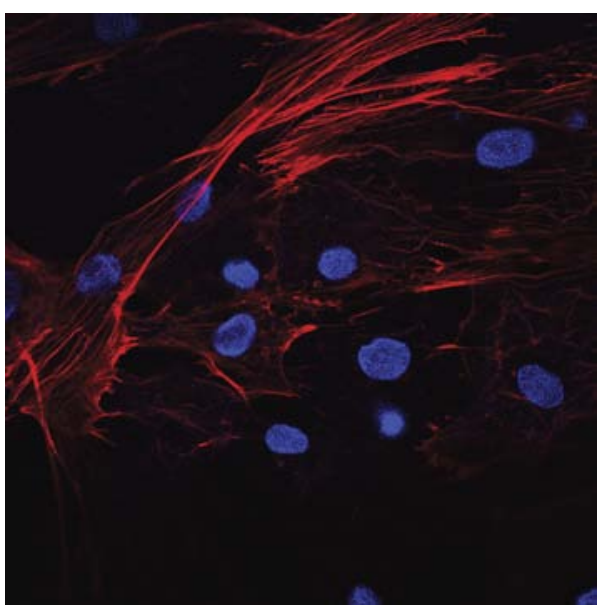

d)

Figure 8. CLSM image of osteoblast cultured on $\mathrm{PP}(\mathrm{HC})_{5}(\mathrm{a}) ; \mathrm{PP}(\mathrm{HC})_{5} \mathrm{H}(\mathrm{b})$; $\mathrm{PP}(\mathrm{c})$; $\mathrm{P}(\mathrm{d})$ films for 7 days. F-actin was stained in red, nucleuses was stained in blue. (Original magnification $\times 400$ )

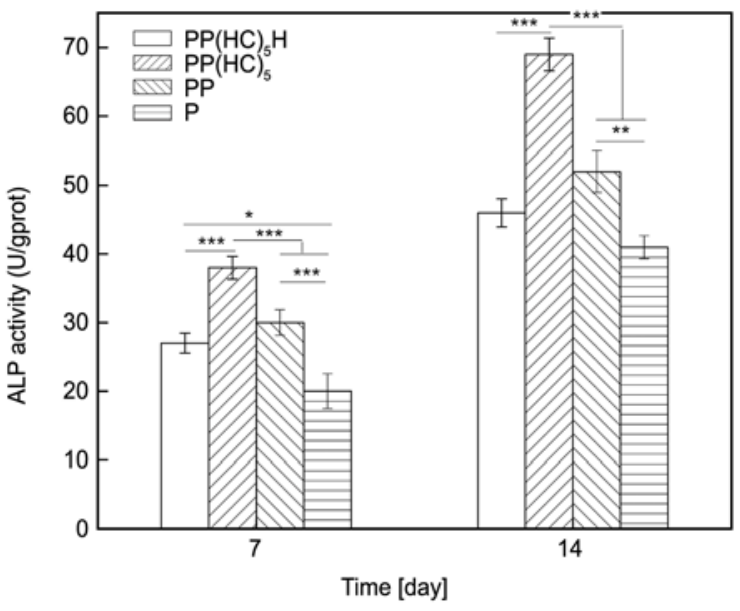

Figure 9. ALP activity of the osteoblast on different films after 7 and 14 days culturing; results are the means $\pm \mathrm{SD}$ of three independent experiments, $[n=3, * \mathrm{P}<0.05, * * \mathrm{P}<0.01, * * * \mathrm{P}<0.001]$

\section{Acknowledgements}

The work was supported by National Natural Science Foundation of China (81171459 and 31270021) and Guangzhou 'Zhujiang River' excellent young scientists program (2011J2200037).

\section{References}

[1] Griffith L. G., Naughton G.: Tissue engineering - Current challenges and expanding opportunities. Science, 295, 1009-1014 (2002).

DOI: $10.1126 /$ science 1069210

[2] Vert M.: Polymeric biomaterials: Strategies of the past vs. strategies of the future. Progress in Polymer Science, 32, 755-761 (2007).

DOI: $10.1016 /$ j.progpolymsci.2007.05.006

[3] Nishikawa T., Nishida J., Ookura R., Nishimura S-I., Wada S., Karino T., Shimomura S.: Honeycomb-patterned thin films of amphiphilic polymers as cell culture substrates. Materials Science and Engineering: C, 8-9, 495-500 (1999).

DOI: $10.1016 / \mathrm{S} 0928-4931(99) 00075-2$ 
[4] Zhang Q., Mochalin V. N., Neitzel I., Hazeli K., Niu J., Kontsos A., Zhou J. G., Lelkes P. I., Gogotsi Y.: Mechanical properties and biomineralization of multifunctional nanodiamond-PLLA composites for bone tissue engineering. Biomaterials, 33, 5067-5075 (2012). DOI: 10.1016/j.biomaterials.2012.03.063

[5] Mallick K. K., Winnett J.: Preparation and characterization of porous Bioglass ${ }^{\circledR}$ and PLLA scaffolds for tissue engineering applications. Journal of the American Ceramic Society, 95, 2680-2686 (2012). DOI: $10.1111 / \mathrm{j} .1551-2916.2012 .05071 . \mathrm{x}$

[6] Chen J-P., Su C-H.: Surface modification of electrospun PLLA nanofibers by plasma treatment and cationized gelatin immobilization for cartilage tissue engineering. Acta Biomaterialia, 7, 234-243 (2011). DOI: $10.1016 /$ j.actbio.2010.08.015

[7] Garric X., Molès J. P., Garreau H., Guilhou J. J., Vert M.: Human skin cell cultures onto PLA PD $_{\text {(PDLLA) }}$ bioresorbable polymers: Influence of chemical and morphological surface modifications. Journal of Biomedical Materials Research Part A, 72, 180-189 (2005). DOI: 10.1002/jbm.a.30216

[8] Jahno V. D., Ribeiro G. B. M., dos Santos L. A., Ligabue R., Einloft S., Ferreira M. R. W., BombonatoPrado K. F.: Chemical synthesis and in vitro biocompatibility tests of poly (L-lactic acid). Journal of Biomedical Materials Research Part A, 83, 209-215 (2007).

DOI: 10.1002/jbm.a.31210

[9] Kim S-S., Park M. S., Jeon O., Choi C. Y., Kim B-S.: Poly(lactide-co-glycolide)/hydroxyapatite composite scaffolds for bone tissue engineering. Biomaterials, 27, 1399-1409 (2006).

DOI: 10.1016/j.biomaterials.2005.08.016

[10] Ravichandran R., Venugopal J. R., Sundarrajan S., Mukherjee S., Ramakrishna S.: Precipitation of nanohydroxyapatite on PLLA/PBLG/collagen nanofibrous structures for the differentiation of adipose derived stem cells to osteogenic lineage. Biomaterials, 33, 846-855 (2012).

DOI: $10.1016 /$ j.biomaterials.2011.10.030

[11] Tzoneva R., Seifert B., Albrecht W., Richau K., Groth T., Lendlein A.: Hemocompatibility of poly(ether imide) membranes functionalized with carboxylic groups. Journal of Materials Science: Materials in Medicine, 19, 3203-3210 (2008).

DOI: $10.1007 / \mathrm{s} 10856-008-3456-8$

[12] Diao H., Si Y., Zhu A., Ji L., Shi H.: Surface modified nano-hydroxyapatite/poly(lactide acid) composite and its osteocyte compatibility. Materials Science and Engineering: C, 32, 1796-1801 (2012).

DOI: $10.1016 / \mathrm{j} . \mathrm{msec} .2012 .04 .065$
[13] Zhao M., Li L., Li X., Zhou C., Li B.: Three-dimensional honeycomb-patterned chitosan/poly(L-lactic acid) scaffolds with improved mechanical and cell compatibility. Journal of Biomedical Materials Research Part A, 98, 434-441 (2011).

DOI: $\underline{10.1002 / \mathrm{jbm} . \mathrm{a} .33132}$

[14] Atthoff B., Hilborn J.: Protein adsorption onto polyester surfaces: Is there a need for surface activation? Journal of Biomedical Materials Research Part B: Applied Biomaterials, 80, 121-130 (2007). DOI: $10.1002 / \mathrm{jbm} . \mathrm{b} .30576$

[15] Khorasani M. T., Mirzadeh H., Irani S.: Plasma surface modification of poly (L-lactic acid) and poly (lactic-co-glycolic acid) films for improvement of nerve cells adhesion. Radiation Physics and Chemistry, 77, 280-287 (2008).

DOI: $10.1016 /$ j.radphyschem.2007.05.013

[16] Zhu H., Ji J., Shen J.: Surface engineering of poly(DLlactic acid) by entrapment of biomacromolecules. Macromolecular Rapid Communications, 23, 819-823 (2002).

DOI: 10.1002/1521-3927(20021001)23:14<819::AIDMARC819>3.0.CO;2-9

[17] Kim B. Y., Bruening M. L.: pH-dependent growth and morphology of multilayer dendrimer/poly(acrylic acid) films. Langmuir, 19, 94-99 (2003).

DOI: $10.1021 / 1 \mathrm{la} 0263530$

[18] Huang R., Li Y., Zhou X., Zhang Q., Jin H., Zhao J., Pan S., Deng H.: LBL fabricated biopolymer-layered silicate based nanofibrous mats and their cell compatibility studies. Carbohydrate Polymers, 90, 957-966 (2012). DOI: $10.1016 / \mathrm{j}$. carbpol.2012.06.026

[19] Hammond P. T.: Engineering materials layer-by-layer: Challenges and opportunities in multilayer assembly. AIChE Journal, 57, 2928-2940 (2011).

DOI: $10.1002 /$ aic. 12769

[20] Ni Y., Liu Z., Gao W., Qu S., Weng J., Feng B.: Characterization of self-assembled decyl bis phosphonatecollagen layers on titanium by QCM-D and osteoblastcompatibility. Applied Surface Science, 257, 92879292 (2011).

DOI: $10.1016 /$ j.apsusc. 2011.05.007

[21] Mhanna R. F., Vörös J., Zenobi-Wong M.: Layer-bylayer films made from extracellular matrix macromolecules on silicone substrates. Biomacromolecules, 12, 609-616 (2011).

DOI: $10.1021 / \mathrm{bm} 1012772$

[22] Mathews S., Bhonde R., Gupta P. K., Totey S.: Extracellular matrix protein mediated regulation of the osteoblast differentiation of bone marrow derived human mesenchymal stem cells. Differentiation, 84, 185-192 (2012).

DOI: $10.1016 /$ j.diff.2012.05.001 
[23] Datta N., Holtorf H. L., Sikavitsas V. I., Jansen J. A., Mikos A. G.: Effect of bone extracellular matrix synthesized in vitro on the osteoblastic differentiation of marrow stromal cells. Biomaterials, 26, 971-977 (2005). DOI: $10.1016 /$ j.biomaterials.2004.04.001

[24] Yu H-S., Jin G-Z., Won J-E., Wall I., Kim H-W.: Macrochanneled bioactive ceramic scaffolds in combination with collagen hydrogel: A new tool for bone tissue engineering. Journal of Biomedical Materials Research Part A, 100, 2431-2440 (2012).

DOI: $10.1002 / \mathrm{jbm} . \mathrm{a} .34163$

[25] Hoyer B., Bernhardt A., Heinemann S., Stachel I., Meyer M, Gelinsky M.: Biomimetically mineralized salmon collagen scaffolds for application in bone tissue engineering. Biomacromolecules, 13, 1059-1066 (2012). DOI: $10.1021 / \mathrm{bm} 201776 \mathrm{r}$

[26] Zhang J., Senger B., Vautier D., Picart C., Schaaf P., Voegel J-C., Lavalle P.: Natural polyelectrolyte films based on layer-by layer deposition of collagen and hyaluronic acid. Biomaterials, 26, 3353-3361 (2005). DOI: 10.1016/j.biomaterials.2004.08.019

[27] Khademhosseini A., Suh K. Y., Yang J. M., Eng G., Yeh J., Levenberg S., Langer R.: Layer-by-layer deposition of hyaluronic acid and poly-L-lysine for patterned cell co-cultures. Biomaterials, 26, 3583-3592 (2004). DOI: 10.1016/j.biomaterials.2003.10.033

[28] Deyl Z., Rohlicek V., Adam M.: Separation of collagens by capillary zone electrophoresis. Journal of Chromatography A, 480, 371-378 (1989).

DOI: 10.1016/S0021-9673(01)84306-5

[29] Liu Z-M., Lee S-Y., Sarun S., Moeller S., Schnabelrauch M., Groth T.: Biocompatibility of poly(L-lactide) films modified with poly(ethylene imine) and polyelectrolyte multilayers. Journal of Biomaterials Science, Polymer Edition, 21, 893-912 (2010). DOI: $10.1163 / 156856209 X 450748$

[30] Jiang F., Hörber H., Howard J., Müller D. J.: Assembly of collagen into microribbons: Effects of $\mathrm{pH}$ and electrolytes. Journal of Structural Biology, 148, 268-278 (2004).

DOI: $10.1016 /$ j.jsb.2004.07.001

[31] Schasfoort R. B. M., Tudos A. J.: Handbook of surface plasmon resonance. RSC Publishing. Cambridge (2008).
[32] Whitson K. B., Lukan A. M., Marlowe R. L., Lee S. A., Anthony L., Rupprecht A.: Binding of the water of primary hydration to the sodium and cesium salts of deoxyribonucleic acid and potassium hyaluronate. Physical Review E, 58, 2370-2377 (1998).

DOI: 10.1103/PhysRevE.58.2370

[33] Taraballi F., Zanini S., Lupo C., Panseri S., Cunha C., Riccardi C., Marcacci M., Campione M., Cipolla L.: Amino and carboxyl plasma functionalization of collagen films for tissue engineering applications. Journal of Colloid and Interface Science, 394, 590-597 (2013). DOI: 10.1016/j.jcis.2012.11.041

[34] Köwitsch A., Yang Y., Ma N., Kuntsche J., Mäder K., Groth T.: Bioactivity of immobilized hyaluronic acid derivatives regarding protein adsorption and cell adhesion. Biotechnology and Applied Biochemistry, 58, 376-389 (2011).

DOI: $10.1002 / \mathrm{bab} .41$

[35] Rezwan K., Chen Q. Z., Blaker J. J., Boccaccini A. R.: Biodegradable and bioactive porous polymer/inorganic composite scaffolds for bone tissue engineering. Biomaterials, 27, 3413-3431 (2006). DOI: 10.1016/j.biomaterials.2006.01.039

[36] Lee C. H., Singla A., Lee Y.: Biomedical applications of collagen. International Journal of Pharmaceutics, 221, 1-22 (2001). DOI: 10.1016/S0378-5173(01)00691-3

[37] Wang R. C-C., Hsieh M-C., Yang S-P., Chuang P-K., Lin J-C., Yang C-Y., Lee T-M.: Characteristics and cyto-compatibility of collagen/Ca-P coatings on $\mathrm{Ti}_{6} \mathrm{Al}_{4} \mathrm{~V}$ substrate. Surface and Coatings Technology, 205, 4683-4689 (2011).

DOI: 10.1016/j.surfcoat.2011.04.029

[38] Sinani V. A., Koktysh D. S., Yun B-G., Matts R. L., Pappas T. C., Motamedi M., Thomas S. N., Kotov N. A.: Collagen coating promotes biocompatibility of semiconductor nanoparticles in stratified LBL films. Nano Letters, 3, 1177-1182 (2003). DOI: $10.1021 / \mathrm{n} 10255045$

[39] Elsdale T. R.: Parallel orientation of fibroblasts in vitro. Experimental Cell Research, 51, 439-450 (1968).

DOI: $10.1016 / 0014-4827(68) 90134-1$

[40] Guido S., Tranquillo R. T.: A methodology for the systematic and quantitative study of cell contact guidance in oriented collagen gels. Correlation of fibroblast orientation and gel birefringence. Journal of Cell Science, 105, 317-331 (1993). 